\title{
Puentes hacia una mejor vida (Bridges to a Better Life): Outcome of a Diabetes Control Peer Support Intervention
}

Guadalupe X. Ayala, PbD, MPH

Leticia Ibarra, MPH ${ }^{2}$

Andrea L. Cherrington, $M D, M P H^{3}$

Humberto Parada, MPH

Lucy Horton, MS, MPH

Ming $\mathrm{Ji}, \mathrm{PbD}^{6}$

Jobn P. Elder, $\mathrm{PbD}, \mathrm{MPH}^{1}$

'San Diego State University College of Health and Human Services and Institute for Behavioral and Community Health, San Diego State University Research Foundation, San Diego, California

${ }^{2}$ Clínicas de Salud del Pueblo, Inc, Brawley, California

${ }^{3}$ Department of Medicine, School of Medicine, University of Alabama at Birmingham, Birmingham, Alabama

${ }^{4}$ University of North Carolina at Chapel Hill

${ }^{5}$ Institute for Behavioral and Community Health, San Diego State University Research Foundation, San Diego, California

${ }^{6}$ University of South Florida College of Nursing, Tampa, Florida

Conflicts of interest: authors report none.

\section{CORRESPONDING AUTHOR}

Guadalupe X. Ayala, PhD, MPH

San Diego State University

Graduate School of Public Health and Institute for Behavioral and Community Health, San Diego State University Research Foundation

9245 Sky Park Court, Suite 220

San Diego, CA 92123

ayala@mail.sdsu.edu

\begin{abstract}
PURPOSE Peer support can promote diabetes control, yet research on feasible and effective peer support models is lacking. This randomized controlled trial tested a volunteer-based model of peer support for diabetes control.

METHODS Thirty-four volunteer peer leaders were recruited and trained to provide support to 5 to 8 patients each through telephone contact, in-person, individual, and group support. Planned dose was 8 contacts, preferably in the first 6 months. Patients with uncontrolled diabetes were randomly sampled from the medical records of 3 community clinics. After a baseline interview and medical records review to obtain baseline values for the primary outcome, $\mathrm{HbA}_{1 c}, 336$ patient participants were randomly assigned to a 12-month peer support intervention or usual care. The assessment protocol was repeated at 6 and 12 months after baseline.
\end{abstract}

RESULTS Thirty peer leaders delivered an average of 4 contacts each per assigned participant (range 1-24). Despite the lack of intervention fidelity, the intervention was effective at reducing glycated hemoglobin $\left(\mathrm{HbA}_{1 \mathrm{c}}\right)$ among intervention as compared with usual care participants $(P=0.05)$. Similar trends were observed in frequency of meeting fruit and vegetable guidelines $(P=0.09)$, a secondary outcome. Counterintuitively, usual care participants reported checking their feet more days out of 7 than intervention participants $(P=0.03)$.

CONCLUSIONS Given the modest changes we observed, combined with other evidence for peer support to promote diabetes control, additional research is needed on how to modify the system of care to increase the level of peer support delivered by volunteers.

Ann Fam Med 2015;13(Suppl_1):S9-S17. doi: 10.1370/afm.1807.

\section{INTRODUCTION}

$\mathrm{D}$ iabetes is prevalent in the United States (9.3\% in 2012). ${ }^{1}$ Rates are higher among Mexican-Americans (13.9\%), among those who live near the US-Mexico border (14.7\% on the US side, for instance $)^{2}$ and among residents of rural areas. ${ }^{3}$ Health care use remains low in rural border communities, ${ }^{4,5}$ and health care is underused for managing diabetes. ${ }^{6,7}$ Research is needed on how to promote glycemic control in rural border communities.

Controlling diabetes requires engaging in healthy behaviors such as exercise, self-monitoring, controlling symptoms, and using medication and health care properly. ${ }^{8}$ An educator, potentially a peer leader, ${ }^{9,10}$ can help persons with diabetes develop the necessary skills to make these behaviors part of their daily lives. In Latino and other racial/ethnic and low-income communities, community health workers ( $\mathrm{CHWs}$ ) often serve as educators and peer leaders, facilitating access to health care, training in selfmanagement behaviors, and providing emotional support. ${ }^{9,11-19} \mathrm{CHWs}$ are typically members of the communities they serve and have direct or indirect experience with the health issue of interest. ${ }^{11}$ Most $\mathrm{CHW}$ interventions with Latinos to promote diabetes control have involved paid CHWs serving in various roles within a health care system or a community-based 
organization. ${ }^{18,20}$ Paid models of peer support, however, may not have sufficient reach and intensity in at-risk communities, including rural communities where health care access is more limited. Volunteer models may be an effective complement to a paid CHW program within a Federally Qualified Health Center (FQHC), although the roles of volunteers need to be considered carefully. ${ }^{10}$ This study tested a variant of the CHW model, ${ }_{1}^{21-23}$ a volunteer peer leader intervention housed within an FQHC.

Puentes bacia una mejor vida (Bridges to a Better Life; "Puentes") was 1 of 8 international studies funded by Peers for Progress to test the feasibility and efficacy of conceptually similar models of peer support to promote diabetes control in diverse local settings. ${ }^{24}$ Puentes was a partnership between a university-affiliated research institute (Institute for Behavioral and Community Health, IBACH) and Clinicas de Salud del Pueblo, Inc. (CDSDP), an FQHC.

\section{METHODS}

\section{Study Design}

Puentes was a randomized, controlled trial with 2 conditions: peer support intervention and usual care. At CDSDP, usual care involves primary and specialty care and access to diabetes education classes. The primary outcome was glycated hemoglobin level $\left(\mathrm{HbA}_{\mathrm{cc}}\right)$ based on a lab visit (or abstracted from the patient's electronic health records if the visit was within the past month); secondary outcomes included health care utilization (eg, emergency room visits) and enactment of diabetes self-management behaviors (eg, modifying diet, checking feet). Protocols were approved by San Diego State University's Institutional Review Board and were consistent with CDSDP's responsibilities under the Health Insurance Portability and Accountability Act (HIPAA). The authors had no conflicts of interest.

\section{Setting}

The study occurred in Imperial County, California, on the US-Mexico border. Most residents of the area are of Mexican origin and report speaking Spanish. ${ }^{25}$ The Puentes study was conducted in the 3 largest CDSDP clinics, which are located in Brawley, El Centro, and Calexico, California. These 3 clinics were identified from among 11 operated by CDSDP as having a large enough patient base for recruitment and the infrastructure needed for outreach activities led by volunteer peer leaders.

\section{Participant Recruitment}

The director of programs queried the medical records of the 3 clinics to obtain a list of adult patients with diabetes who had received services during the previous 3 months. Patients were excluded if their last $\mathrm{HbA}_{1 \mathrm{c}}$ was less than 7 or if they did not live in 1 of the 3 cities where the participating clinics were located, to minimize travel costs to the peer leaders. ${ }^{5}$ A random sample of 1,202 patients taken relatively evenly from the 3 clinics received a study invitation letter from CDSDP and, in $96 \%$ of cases, a follow-up telephone call from an English/Spanish bilingual, HIPAA-certified research assistant. A further method of recruiting these sampled patients involved a HIPAA-certified research assistant approaching the randomly sampled patient in the clinic waiting room.

Patients interested in participating - a total of 1,153 - scheduled face-to-face appointments to complete the eligibility screening. Requirements included residence in 1 of the 3 target cities; plans to remain in the study area for 1 year $r_{i}$ ability to read and speak Spanish, English or both; no current involvement in another diabetes intervention, and no physical or mental disability that would limit participation. From among this sample, we identified 477 (41\%) who were eligible. Of those, 336 (70\%) agreed to participate (Figure 1). All patients who consented completed the baseline assessment protocol involving a face-to-face interview (described further below) and a lab visit to obtain measures of $\mathrm{HbA}_{1 \mathrm{c}}$ and blood pressure if none were available from the previous month. If measures were available, the information was abstracted from the health record. Patients were then randomized to intervention or usual care. Randomization was conducted by the study biostatistician and stratified by clinic. Patients randomized to the intervention received a call from their peer leader as detailed below, while those randomized to usual care received a thank-you letter and reminder of the 6 -month evaluation visit.

\section{Intervention}

Volunteer peer leaders were assigned to work with 5 to 8 patients each over a 12 -month period, with the goal of achieving 8 contacts during the first 6 months. The intervention considered the 4 key functions of peer support: assistance with diabetes management in daily living such as problem-solving barriers to medication use; social/ emotional support such as how to communicate effectively with family members about one's needs; linkages to health care such as knowing where to go to obtain specialty services $;$ and ongoing support over time. ${ }^{24,26}$

\section{Recruitment of Peer Leaders}

Peer leader recruitment was based on volunteerism research, which suggests that volunteers may be more motivated and more satisfied with their volunteer experience if they became involved to better them- 


\section{Figure 1. Participant flow in the Puentes trial.}

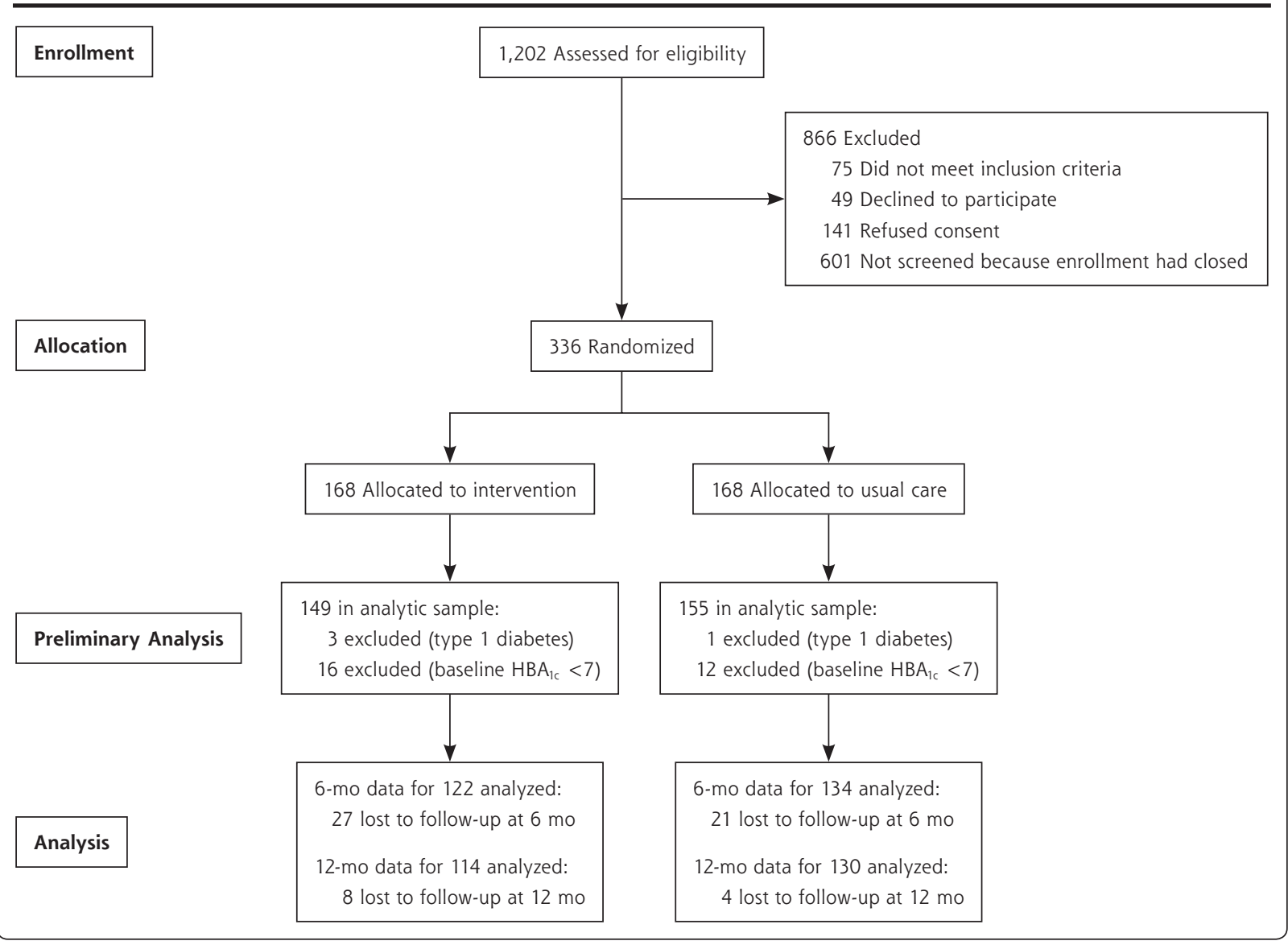

selves. ${ }^{27}$ Thus, despite the collectivistic nature of the Latino community, ${ }^{28}$ recruitment materials were framed as an opportunity to develop new skills and network as peer leaders. We sought individuals with previous diabetes education, although they were not required to have diabetes themselves. Letters were mailed to CDSDP patients who had completed the diabetes education classes, CDSDP staff members recruited from among their social networks, and CDSDP clinicians referred patients.

Interested individuals were screened for eligibility. Eligible individuals were CDSDP patients who lived with or had provided extensive care for someone with diabetes, who were willing to provide support to 5 to 8 patients for at least 12 months, and who planned to remain in the study area for 1 year. Potential peer leaders completed an application and participated in an interview with the director of programs, a CHW, and a research team member. Those selected as peer leaders provided written informed consent, completed a baseline assessment, a medical records release form, and an image and voice consent form. CDSDP required HIPAA training and a tuberculosis test.
The study sought to recruit 30 individuals; $_{\text {in }}$ the end 34 agreed to participate. The peer leaders were mostly female (97\%), married (79\%), high school educated $(88 \%)$, and Mexican-born $(82 \%)_{i} 91 \%$ preferred speaking Spanish. Only 3 had diabetes.

\section{Training of Peer Leaders}

Peer leaders received 40 to 50 hours of training. As depicted in Figure 2, training materials included a 10-lesson manual that covered both diabetes-related content, such as the importance of diet in diabetes control, and skill development components, such as how to estimate food portion sizes more accurately. In addition, 2 booster trainings were developed on how to lead cooking and physical activity support groups. ${ }^{29}$ Each training session incorporated a number of pedagogical approaches consistent with adult learning theory including interactive components, opportunities to share personal experiences, and opportunities to practice skills.

\section{Delivery of Peer Support}

With peer leaders selected and trained, each newly recruited patient was assigned to work with the next 


\section{Figure 2. Peer leader training curriculum.}

\section{Curriculum}

1. Building your opportunities as a volunteer

2. Providing support for diabetes

3. Diabetes and nutrition*

4. Diabetes and physical activity

5. Diabetes and emotional health

6 . Diabetes and medical management

7. How to conduct a home visit**

8. How to conduct a visit to the clinic

9. How to conduct a support group

10. How to monitor your activities

\section{*Sample outline}

1. Cover page with story

2. Table of contents

3. Your motivation

4. Building your foundation

- Dietary behaviors at home

- Food portion size training

- Dietary behaviors outside the home

- Other approaches to improving diet

5. Putting it into practice

6 . Reaffirming your motivation

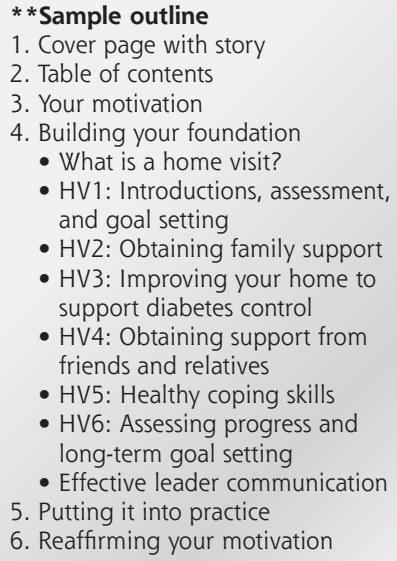

* *Sample outline

1. Cover page with story

2. Table of contents

3. Your motivation

4. Building your foundation

- What is a home visit?

- HV1: Introductions, assessment, and goal setting

- HV2: Obtaining family support

- HV3: Improving your home to support diabetes control

- HV4: Obtaining support from friends and relatives

- HV5: Healthy coping skills

- HV6: Assessing progress and long-term goal setting

- Effective leader communication

5. Putting it into practice

6. Reaffirming your motivation

tion (ie, at baseline), and at 6 and 12 months post-baseline.

\section{Patient Interviews}

Patients were asked about the number of planned and unplanned diabetes care visits, including doctor, emergency department (ED), and hospital visits, they had during the past 6 months. The same time frame was used at all 3 points to allow comparability over time. As with other Peers for Progress studies, self-management questions came from the Summary of Diabetes Self-Care Activities scale, ${ }^{32}$ which has been validated for use with Latinos. ${ }^{33,34}$ Specifically, the patients were asked the number of days in the past week they consumed 5 or more servings of fruits and vegetables, consumed high fat foods, participated in 30 minutes of daily physical activity, tested blood sugar, and checked their feet. Medication adherence was assessed using the 4-item Morisky Medication Adherence Scale. ${ }^{35}$ Responses were dichotomized as adherent (1) or not adherent (0) based on an affirmative

available peer leader. In addition to the targeted 8 meetings in the first 6 months, peer leaders were encouraged to schedule additional contacts as needed during the subsequent 6 months. Peer leaders were trained on various intervention modalities including telephone calls, home visits, support groups, and clinic tours; peer leaders selected modes of intervention based on the patient's preferences and theirs.

\section{Evaluation Procedures}

\section{Assessing Feasibility}

To track intervention delivery, ${ }^{30,31}$ the peer leaders maintained patient contact logs and submitted them to the peer leader coordinator during weekly or biweekly meetings. The logs tracked the number of contact attempts, whether contact occurred, and if so, the length and modality of contact. To obtain a measure of dose received, all unique interpersonal contacts (telephone, one-on-one visit, support group, clinic visit) were summed.

\section{Assessing Efficacy}

Patient interviews, medical record reviews, and lab visits were conducted at 3 points: before randomiza- response to any item.

Demographic characteristics included age, sex, education level (6th grade or less vs more than 6th grade), marital status, employment status, household size, and whether the family lives in poverty, defined using the US Census Bureau's 2010 annual income thresholds for household size. Sociocultural characteristics included ethnicity (Latino/Hispanic vs not), foreign-born vs US-born, and if foreign born, age at arrival, and years living in the Unites States. Health care and diabetes characteristics included whether the patient had health insurance, whether he or she had a personal doctor, and whether cost was a barrier to seeking health care. Finally, patients were asked age at diagnosis, to determine disease duration in years, and what type of diabetes they had (type 1, type 2 or gestational).

\section{Lab Visit or Medical Record Review}

The lab visit involved a blood draw and measurement of height, weight, and blood pressure (BP). At each data-collection point, lab data were obtained on the same day as the interview, with 1 exception: a lab visit was not required if the participant had values for $\mathrm{HbA}_{1 \mathrm{c}}$ and $\mathrm{BP}$ that were no more than 1 
month old. In such cases, the test results closest to the interview date were used in the analyses. Health care use including ophthalmology and podiatry visits and diabetes education sessions were also abstracted from medical records for the year preceding the baseline interview and the year between baseline and the 12-month point.

\section{Analyses}

Analyses were performed using IBM SPSS Statistics version 20 (IBM Corp) and SAS software version 9.3 (SAS Institute Inc.). Descriptive analyses assessed the distribution and normality of the variables, leading us to exclude 4 patients ( 3 intervention and 1 usual care) with type 1 diabetes and 28 patients (16 intervention and 12 usual care) with $\mathrm{HbA}_{1 \mathrm{c}}$ values less than $7 \%$ at baseline. The latter occurred because the $\mathrm{HbA}_{1 \mathrm{c}}$ values used to identify eligible patients were different from the values eventually obtained for participants at baseline. Our final analytic sample was 304 patients.

To assess feasibility, we examined peer leader intervention delivery using descriptive statistics. To examine efficacy, each outcome was examined using mixed effects models for normal outcomes or generalized linear mixed effects models for non-normal outcomes. Outcome analyses were based on the intention-to-treat approach. The continuous outcomes of $\mathrm{HbA}_{1 \mathrm{c}}$, systolic $\mathrm{BP}$, and diastolic BP were log-transformed so that their distributions were closer to the normal distribution, which is a requirement of mixed effects models. The independent variables included these: Group (intervention vs usual care), Time (the number of days from baseline to the measurement date, approximately 6 and 12 months post-baseline), the Group and Time interaction, and the variables personal doctor and poverty status to control for group differences at baseline. We fitted a 3-level model recognizing the clustering effects of repeated measures within the same individuals and individuals within the same clinics. The model fitting was performed using SAS 9.2 PROC MIXED and PROC GLIMMIX. We also examined specified secondary outcomes-changes in health care utilization and diabetes self-management behaviors including medication adherence. Finally, we examined whether there was a dose-response relationship between peer leader contact and the outcomes.

\section{RESULTS}

Participant characteristics are shown in Table 1. There was some indication that a greater percentage of intervention participants than usual care participants reported having a personal doctor $(P=.09)$ while a greater percentage of usual care participants reported living below poverty thresholds $(P=.08)$; no other group differences were observed.

\section{Feasibility}

Although 34 peer leaders were trained to provide support, 4 (12\%) provided none. Reasons included challenges in connecting with their peers or changes in the peer leaders' availability given family and work responsibilities. Number of patient contacts (attempts vs completions) and modality of delivery were all examined following CONSORT guidelines. ${ }^{37}$ Although peer leaders attempted to contact patients a median of 12 times each, they were unable to achieve the planned dose of 8 contacts during the first 6 months (Table 2). The median number of achieved contacts was 4 . Contact was primarily in the form of telephone conversations followed by one-on-one visits.

Using criteria recommended by others, ${ }^{37}$ intervention participants with 6 or more interpersonal contacts
Table 1. Patient Characteristics Overall and by Study Group ( $N=304)$

\begin{tabular}{|c|c|c|c|}
\hline & $\begin{array}{c}\text { Total } \\
(\mathrm{N}=304)\end{array}$ & $\begin{array}{l}\text { Intervention } \\
\quad(n=149)\end{array}$ & $\begin{array}{c}\text { Usual Care } \\
(n=155)\end{array}$ \\
\hline \multicolumn{4}{|l|}{ Demographic characteristics } \\
\hline Age in years, mean (SD) & $56.3(11.9)$ & $56.7(11.8)$ & $55.9(12.1)$ \\
\hline Female, No. (\%) & $193(63)$ & $98(66)$ & $95(61)$ \\
\hline 6 th grade education or less, No. (\%) & $126(41)$ & $61(41)$ & $65(42)$ \\
\hline Married, No. (\%) & $188(62)$ & $94(63)$ & $94(61)$ \\
\hline Employed, No. (\%) & $71(23)$ & $34(23)$ & $37(24)$ \\
\hline Household size, mean (SD) & $3.5(1.8)$ & $3.5(1.9)$ & $3.6(1.8)$ \\
\hline Living in poverty, No. (\%) & $189(62)$ & $85(57)$ & $104(67)$ \\
\hline \multicolumn{4}{|l|}{ Sociocultural characteristics } \\
\hline Latino/Hispanic, No. (\%) & $292(96)$ & $145(97)$ & $147(95)$ \\
\hline Foreign born, No. (\%) & $233(77)$ & $112(75)$ & $121(78)$ \\
\hline If foreign born, age at arrival, mean (SD) & $26.8(14.4)$ & $28.1(15.4)$ & $25.7(13.3)$ \\
\hline If foreign born, y in United States, mean (SD) & $28.6(14.6)$ & $27.1(15.2)$ & $30.0(13.9)$ \\
\hline \multicolumn{4}{|l|}{ Health care characteristics } \\
\hline Any health insurance, No. (\%) & $207(68)$ & $107(72)$ & $100(65)$ \\
\hline Have a personal doctor, No. $(\%)^{\mathrm{b}}$ & $206(68)$ & $108(72)$ & $98(63)$ \\
\hline Cost is a barrier to health care, No. (\%) & $78(26)$ & $39(26)$ & $39(25)$ \\
\hline Years with diabetes diagnosis, mean (SD) & $12.5(10.2)$ & $12.8(9.8)$ & $12.3(10.6)$ \\
\hline \multicolumn{4}{|l|}{$\mathrm{a} P=.09$} \\
\hline \multicolumn{4}{|c|}{ For all other comparisons between usual care and intervention group, $P>.10$. } \\
\hline
\end{tabular}


were classified as having received the intervention with fidelity. Of those who received any interpersonal contact, 36\% (53) received the intervention with fidelity. They differed from those who did not in marital status $(74 \%$ were married vs $57 \% ; P=.05)$ and country of origin ( $83 \%$ foreign born vs $71 \% ; P=.09)$. No other differences were observed.

Retention of patients in both conditions was excellent (Figure 1); however, slightly more usual care participants than intervention participants were retained at the 12 -month point ( $84 \%$ vs $77 \%$ ). No significant

\section{Table 2. Puentes Intervention Delivery $(n=149)$}

\begin{tabular}{lc}
\hline Contact data & \\
\hline $\begin{array}{l}\text { Number of interpersonal contacts per participant, } \\
\text { median (range) }\end{array}$ & $4(1-24)$ \\
Participants with no interpersonal contact, No. (\%) & $10(7)$ \\
Participants who received interpersonal contacts, by & \\
$\quad$ type of contact, No. (\%) & \\
Telephone & $137(92)$ \\
One-on-one & $76(51)$ \\
Support Groups & $27(18)$ \\
Clinic visits & $12(8)$ \\
\hline a Not mutually exclusive. & \\
\hline
\end{tabular}

differences were observed between those who dropped out and those retained at 12 months.

\section{Efficacy}

\section{Clinical Data}

Table 3 shows unadjusted means or proportions with each outcome for intervention and usual care groups at baseline, 6, and 12 months. Table 4 shows the results of regression analyses that adjusted for clustering at the patient and clinic levels and for baseline differences between the randomly assigned groups. $\mathrm{HbA}_{1 \mathrm{c}}$ levels improved among intervention vs usual care participants over the 12-month period $(0.4 \%$ vs $0 \%, P=.05$; Tables 3 and 4$)$. There were no intervention effects on systolic or diastolic BP.

\section{Health Care Utilization}

Among both groups, the number of planned visits decreased over time $(P=.02)$. Intervention effects on unplanned diabetes care visits, dilated eye exams, foot exams, and diabetes classes could not be tested in these models as the data did not meet statistical assumptions.

\section{Diabetes Self-Management Behaviors}

Intervention participants reported consuming 5 or more fruits and vegetables per day on more days of

Table 3. Baseline, Intermediate and Long-Term Clinical and Behavioral Outcomes by Study Condition $(\mathrm{N}=304)$

\begin{tabular}{|c|c|c|c|c|c|c|}
\hline & \multicolumn{3}{|c|}{ Intervention } & \multicolumn{3}{|c|}{ Control } \\
\hline & $\begin{array}{l}\text { Baseline } \\
\mathrm{N}=149\end{array}$ & $\begin{array}{c}6 \text { mo } \\
n=133\end{array}$ & $\begin{array}{c}12 \mathrm{mo} \\
\mathrm{n}=122\end{array}$ & $\begin{array}{l}\text { Baseline } \\
\mathrm{N}=155\end{array}$ & $\begin{array}{c}6 \mathrm{mo} \\
\mathrm{n}=142\end{array}$ & $\begin{array}{r}12 \mathrm{mo} \\
\mathrm{n}=141\end{array}$ \\
\hline \multicolumn{7}{|l|}{ Health status (medical record) } \\
\hline $\mathrm{HbA}_{1 \mathrm{c}}$, mean $(\mathrm{SD})$ & $8.7(1.6)$ & $8.6(2.0)$ & $8.3(1.9)$ & $8.7(1.5)$ & $8.6(1.9)$ & $8.7(2.0)$ \\
\hline Systolic blood pressure, mean (SD) & $131.5(17.7)$ & $130.5(19.0)$ & $131.3(20.1)$ & $127.9(18.8)$ & $131.3(20.3)$ & $131.1(21.5)$ \\
\hline Diastolic blood pressure, mean (SD) & $74.9(9.0)$ & $73.9(9.0)$ & $74.2(9.5)$ & $74.2(8.6)$ & $74.9(8.6)$ & $73.6(9.6)$ \\
\hline \multicolumn{7}{|l|}{ Health care use (medical record) } \\
\hline Dilated eye exam, No. (\%) & $62(42)$ & -- & $54(36)$ & $69(45)$ & -- & $45(29)$ \\
\hline Foot exam, No. (\%) & $32(21)$ & -- & $37(25)$ & $32(21)$ & -- & $36(23)$ \\
\hline $\begin{array}{l}\text { Diabetes/Nutrition education, } \\
\text { No. (\%) }\end{array}$ & $82(55)$ & -- & $29(19)$ & $86(55)$ & -- & $31(20)$ \\
\hline \multicolumn{7}{|l|}{ Health care use (interview) } \\
\hline $\begin{array}{l}\text { Planned diabetes care visits, } \\
\text { mean (SD) }\end{array}$ & $3.8(2.2)$ & $3.4(2.2)$ & $3.5(4.1)$ & $3.6(2.8)$ & $3.4(2.4)$ & $3.4(2.7)$ \\
\hline $\begin{array}{l}\text { Unplanned diabetes care visits, } \\
\text { mean (SD) }\end{array}$ & $0.6(0.9)$ & $0.4(1.0)$ & $0.3(0.9)$ & $0.9(1.7)$ & $0.4(1.1)$ & $0.4(0.9)$ \\
\hline \multicolumn{7}{|c|}{ Diabetes management behaviors (interview) } \\
\hline \multicolumn{7}{|c|}{ Days in past week ... } \\
\hline $\begin{array}{l}5+\text { fruits } \varepsilon \text { vegetables consumed, } \\
\text { mean (SD) }\end{array}$ & $3.6(2.5)$ & $3.8(2.7)$ & $4.0(2.9)$ & $4.0(2.5)$ & $3.7(2.9)$ & $3.8(2.8)$ \\
\hline High fat foods consumed, mean (SD) & $2.5(1.9)$ & $2.4(2.0)$ & $2.1(1.7)$ & $2.4(2.0)$ & $2.4(2.1)$ & $2.4(2.1)$ \\
\hline $\begin{array}{l}30 \text { minutes of physical activity, } \\
\text { mean (SD) }\end{array}$ & $2.5(2.7)$ & $3.3(2.8)$ & $2.7(2.7)$ & $3.1(3.0)$ & $3.4(2.9)$ & $3.3(3.0)$ \\
\hline Blood sugar checked, mean (SD) & $4.6(2.8)$ & $4.7(2.7)$ & $5.0(2.6)$ & $4.8(2.9)$ & $5.0(2.9)$ & $5.2(2.6)$ \\
\hline Feet checked, mean (SD) & $5.3(2.8)$ & $5.8(2.3)$ & $5.6(2.4)$ & $5.1(2.9)$ & $5.8(2.4)$ & $6.4(1.7)$ \\
\hline Medication adherence, No. (\%)a & $62(42)$ & $67(55)$ & $62(53)$ & $57(37)$ & $77(57)$ & $70(53)$ \\
\hline
\end{tabular}


Table 4. Intervention Effects on $\mathrm{HbA}_{1 c}$, Blood Pressure, Health Care Use, and Diabetes Management Behaviors ( $\mathrm{N}=304)$

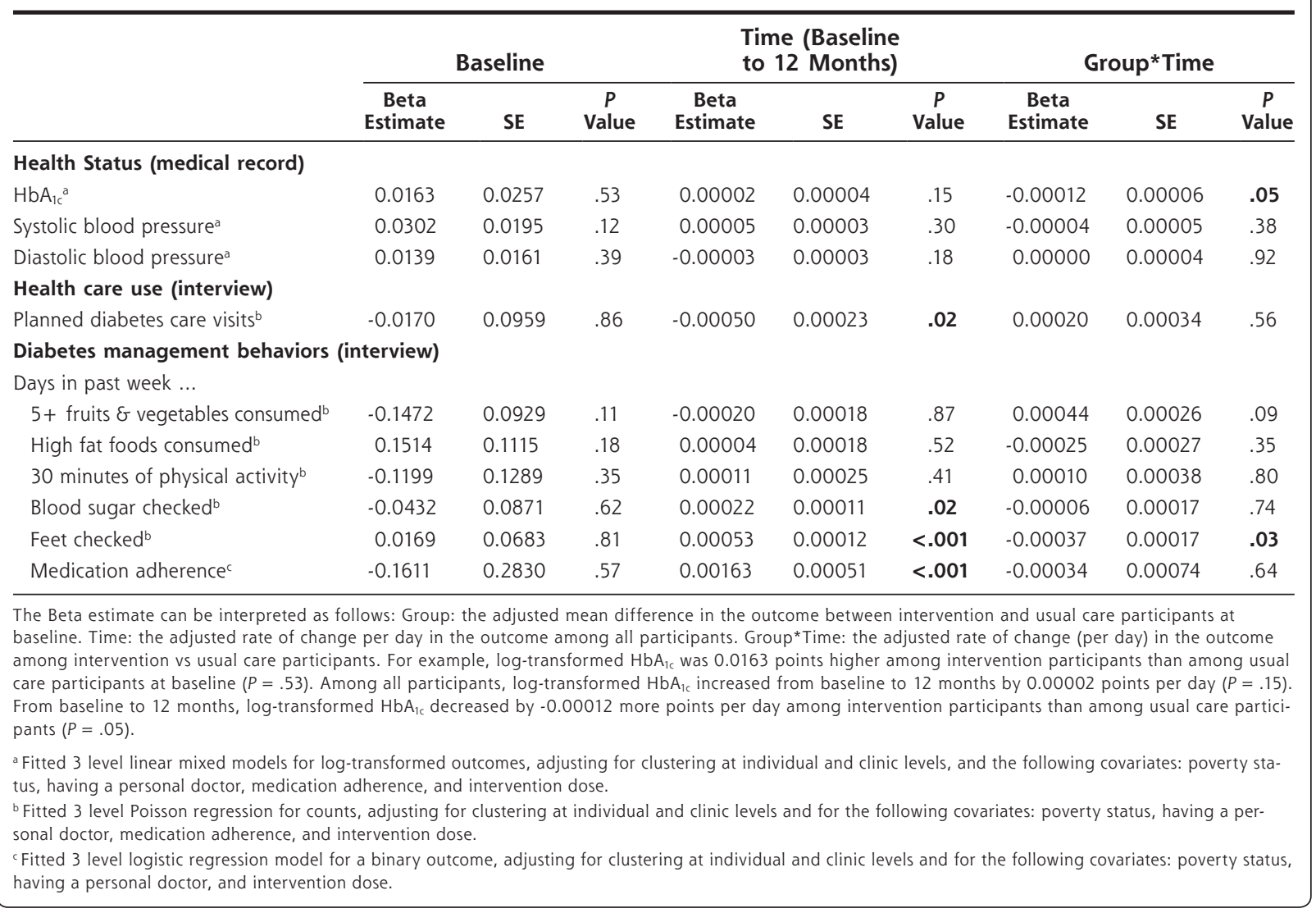

the week than usual care participants, but this was not statistically significant $(P=.09)$. Improvements were observed in both groups in the number of days checking blood sugar $(P=.02)$, checking feet $(P<.001)$, and medication adherence $(P<.001)$. Unexpectedly, the rate of feet checking increased more among usual care than among intervention participants $(P=.03)$.

\section{Dose-Response Relationship}

Dose was related to 1 variable; more contacts were associated with less frequent high-fat-food consumption $(P=0.02$; data not shown).

\section{DISCUSSION}

Ample research demonstrates the need for additional sources of diabetes care, particularly in rural border communities where specialty services are limited and diabetes care standards may not meet ADA guidelines. ${ }^{38-41}$ Peer support has been identified as effective for promoting glycemic control. This study adds to existing research by using a rigorous study design to test a volunteer-based peer support model to control diabetes. In this study, improvements were observed in
$\mathrm{HbA}_{\mathrm{cc}}$ from baseline to 12 months in the intervention but not the usual care participants. However, improvements were modest and perhaps of limited clinical significance (a decrease in $\mathrm{HbA}_{1 \mathrm{c}}$ of 0.04 over 12 months). The effect on $\mathrm{HbA}_{1 \mathrm{c}}$ echoes findings from previous research involving Mexican-Americans ${ }^{42}$ and a rural population, ${ }^{43}$ although the effect is not as strong as in other studies. $12,13,22,44-47$

\section{Limitations}

A major limitation of this study was intervention fidelity. We planned for 8 contacts in the first 6 months, and on average, only 4 contacts were achieved.

In-person contacts were emphasized in the training, so the peer leaders may not have relied on telephone contact as readily as if it had been planned as in a previous study. ${ }^{22}$ Implementing a volunteer-based intervention is challenging where distances and lack of public transportation are major barriers to bringing people together. A second limitation is the initial inclusion of 28 patients with $\mathrm{HbA}_{1 \mathrm{c}}$ below the cut-off for recruitment. This occurred because patients' $\mathrm{HbA}_{\mathrm{ic}}$ levels changed between the initial medical record review and baseline data collection, and this discrepancy was not 
found until after the trial ended. A final limitation is the difference in drop-out rates between intervention and usual care participants, which might have been due to the burden of study involvement on intervention participants. Nonetheless, we found no significant differences at baseline between those who completed the study and those who dropped out.

\section{Implications}

Research is needed on the optimal dose of peer support and the modalities of support most beneficial for the type of change sought. Some researchers argue for a minimum of 10 contacts over a period longer than 6 months. ${ }^{9,48}$ The type of contact has implications for costs. ${ }^{49}$ This study found modest improvements with 4 mostly telephonic contacts, suggesting that researchers should consider telephone-based interventions, particularly for rural community members, given their feasibility and effectiveness for promoting diabetes control. ${ }^{48}$ Researchers and practitioners should also consider paying or incentivizing peer leaders to maximize dose delivered in efficacy studies, ${ }^{37}$ and practitioners should consider methods for sustaining their involvement. Consistent with current strategies to address childhood obesity, ${ }_{1}^{50}$ clinical system redesign ${ }^{51}$ is needed to maximize the potential of programs such as Puentes to be successfully implemented and sustained. Research reviews support the effectiveness of organizational change interventions, ${ }^{9,52,53}$ allowing for the involvement of paraprofessionals, including paid CHWs, in chronic care teams. Although volunteer peer support models may effectively promote healthy behaviors such as physical activity, ${ }^{29}$ they may not fit a chronic care model. Finally, more research is needed on choosing the most important behaviors to target. For instance, we could have de-emphasized fruit and vegetable consumption, given that in this locale the rates of fruit and vegetable consumption already meet guidelines. ${ }^{54}$

To read or post commentaries in response to this article, see it online at http://www.annfammed.org/content/13/Suppl_1/S9.

\section{Trial registry number: NCT02193984}

Key words: peer support; diabetes control; Hispanic Americans

Submitted August 20, 2014; submitted, revised April 3, 2015; accepted April 23, 2015.

Funding support: Funding for this research was provided by the American Academy of Family Physicians Foundation through the Peers for Progress program with support from the Eli Lilly and Company Foundation.

Previous presentations: American Diabetes Association; June 15, 2014; San Francisco, California.

Acknowledgments: The authors dedicate this paper to Maria Belen Luna, Community Health Worker Coordinator of CDSDP. The authors also would like to thank the peer leaders, staff, and administration of Clinicas de Salud del Pueblo, Inc for supporting public health research.

\section{REFERENCES}

1. Centers for Disease Control and Prevention. National Diabetes Statistics Report: Estimates of Diabetes and Its Burden in the United States, 2014. Atlanta, GA; 2014. http://www.cdc.gov/diabetes/pubs/statsreport14/national-diabetes-report-web.pdf. Accessed Aug 1, 2014.

2. Díaz-Apodaca BA, Ebrahim S, McCormack V, de Cosío FG, RuizHolguín R. Prevalence of type 2 diabetes and impaired fasting glucose: cross-sectional study of multiethnic adult population at the United States-Mexico border. Rev Panam Salud Publica. 2010;28(3):174-181.

3. Lynch CP, Gebregziabher M, Axon RN, Hunt KE, Payne E, Egede LE. Geographic and racial/ethnic variations in patterns of multimorbidity burden in patients with type 2 diabetes. J Gen Intern Med. 2015;30(1):25-32.

4. Molina MA, Ayala GX, Baquero B, Madanat H, Garcini L. The link between border crossing and obesity. J Immigr Minor Health. 2015;17(2):614-617.

5. Melvin CL, Corbie-Smith G, Kumanyika SK, et al; Workshop Working Group on CVD Prevention in High-Risk Rural Communities. Developing a research agenda for cardiovascular disease prevention in highrisk rural communities. Am J Public Health. 2013;103(6):1011-1021.

6. Su D, Pratt W, Salinas J, Wong R, Pagán JA. Rural-urban differences in health services utilization in the US-Mexico border region. J Rural Health. 2013;29(2):215-223.

7. Mier N, Wang $X$, Smith $M L$, et al. Factors influencing health care utilization in older Hispanics with diabetes along the Texas-Mexico border. Popul Health Manag. 2012;15(3):149-156.

8. Health Quality Ontario. Behavioural interventions for type 2 diabetes: an evidence-based analysis. Ont Health Technol Assess Ser. 2009;9(21):1-45. http://www.ncbi.nlm.nih.gov/pubmed/23074526.

9. Glazier RH, Bajcar J, Kennie NR, Willson K. A systematic review of interventions to improve diabetes care in socially disadvantaged populations. Diabetes Care. 2006;29(7):1675-1688.

10. Tang TS, Ayala GX, Cherrington A, Rana G. A review of volunteerbased peer support interventions in diabetes. Diabetes Spectr. 2011;24(2):85-98.

11. Ayala GX, Vaz L, Earp JA, Elder JP, Cherrington A. Outcome effectiveness of the lay health advisor model among Latinos in the United States: an examination by role. Health Educ Res. 2010;25(5):815-840.

12. Prezio EA, Cheng D, Balasubramanian BA, Shuval K, Kendzor DE, Culica D. Community Diabetes Education (CoDE) for uninsured Mexican Americans: a randomized controlled trial of a culturally tailored diabetes education and management program led by a community health worker. Diabetes Res Clin Pract. 2013;100(1):19-28.

13. Spencer MS, Rosland A-M, Kieffer EC, et al. Effectiveness of a community health worker intervention among African American and Latino adults with type 2 diabetes: a randomized controlled trial. Am J Public Health. 2011;101(12):2253-2260.

14. Hunt CW, Grant JS, Appel SJ. An integrative review of community health advisors in type 2 diabetes. J Community Health. 2011;36(5):883-893.

15. Pérez-Escamilla R, Damio G, Chhabra J, et al. Impact of a community health workers-led structured program on blood glucose control among latinos with type 2 diabetes: the DIALBEST trial. Diabetes Care. 2015;38(2):197-205.

16. Carrasquillo O, Patberg E, Alonzo Y, Li H, Kenya S. Rationale and design of the Miami Healthy Heart Initiative: a randomized controlled study of a community health worker intervention among Latino patients with poorly controlled diabetes. Int J Gen Med. 2014;7:115-126.

17. Nelson K, Drain N, Robinson J, et al. Peer Support for Achieving Independence in Diabetes (Peer-AID): design, methods and baseline characteristics of a randomized controlled trial of community health worker assisted diabetes self-management support. Contemp Clin Trials. 2014;38(2):361-369. 
18. Gonzalez LS, Berry DC, Davison JA. Diabetes self-management education interventions and glycemic control among hispanics: a literature review. Hisp Health Care Int. 2013;11(4):157-166.

19. Cherrington A, Ayala GX, Amick H, Allison J, Corbie-Smith G, Scarinci I. Implementing the community health worker model within diabetes management: challenges and lessons learned from programs across the United States. Diabetes Educ. 2008;34(5):824-833.

20. Cherrington A, Ayala GX, Amick H, Scarinci I, Allison J, CorbieSmith $\mathrm{G}$. Applying the community health worker model to diabetes management: using mixed methods to assess implementation and effectiveness. J Health Care Poor Underserved. 2008;19(4):1044-1059.

21. Rosenthal EL, Brownstein JN, Rush CH, et al. Community health workers: part of the solution. Health Aff (Millwood). 2010;29(7):1338-1342.

22. Thom DH, Ghorob A, Hessler D, De Vore D, Chen E, Bodenheimer TA. Impact of peer health coaching on glycemic control in lowincome patients with diabetes: a randomized controlled trial. Ann Fam Med. 2013;11(2):137-144.

23. Cherrington A, Ayala GX, Elder JP, Arredondo EM, Fouad M, Scarinci I. Recognizing the diverse roles of community health workers in the elimination of health disparities: from paid staff to volunteers. Ethn Dis. 2010;20(2):189-194. http://www.ncbi.nlm.nih.gov/pmc/ articles/PMC3695477/.

24. Boothroyd RI, Fisher EB. Peers for progress: promoting peer support for health around the world. Fam Pract. 2010;27(Suppl 1):i62-i68.

25. US Census Bureau. Imperial County, California, 2012. http://quickfacts.census.gov/qfd/states/06/06025.html. Accessed May 1, 2014.

26. Fisher EB, Coufal MM, Parada $H$, et al. Peer support in health care and prevention: cultural, organizational, and dissemination issues. Annu Rev Public Health. 2014;35:363-383. 10.1146/ annurev-publhealth-032013-182450.

27. Clary EG, Snyder M, Ridge R. Volunteers' motivations: a functional strategy for the recruitment, placement, and retention of volunteers. Nonprofit Manag Leadersh. 1992;2(4):333-350. http://www. ncbi.nlm.nih.gov/pubmed/10119110.

28. Triandis HC, Bontempo R, Betancourt $\mathrm{H}$, et al. The measurement of the etic aspects of individualism and collectivism across cultures. Aust J Psychol. 1986;38(3):257-267.

29. Ayala GX; San Diego Prevention Research Center Team. Effects of a promotor-based intervention to promote physical activity: Familias Sanas y Activas. Am J Public Health. 2011;101(12):2261-2268.

30. Lemay CA, Ferguson WJ, Hargraves JL. Community health worker encounter forms: a tool to guide and document patient visits and worker performance. Am J Public Health. 2012;102(7):e70-e75.

31. Baquero B, Ayala GX, Arredondo EM, et al. Secretos de la Buena Vida: processes of dietary change via a tailored nutrition communication intervention for Latinas. Health Educ Res. 2009;24(5):855-866.

32. Toobert DJ, Hampson SE, Glasgow RE. The summary of diabetes self-care activities measure: results from 7 studies and a revised scale. Diabetes Care. 2000;23(7):943-950. http://www.ncbi.nlm.nih. gov/pubmed/10895844.

33. Ell K, Katon W, Xie B, et al. Collaborative care management of major depression among low-income, predominantly Hispanic subjects with diabetes: a randomized controlled trial. Diabetes Care. 2010;33(4):706-713.

34. Sarkar U, Fisher L, Schillinger D. Is self-efficacy associated with diabetes self-management across race/ethnicity and health literacy? Diabetes Care. 2006;29(4):823-829. http://www.ncbi.nlm.nih.gov/ pubmed/16567822.

35. Morisky DE, Green LW, Levine DM. Concurrent and predictive validity of a self-reported measure of medication adherence. Med Care. 1986;24(1):67-74. http://www.ncbi.nlm.nih.gov/pubmed/3945130.

36. Moher D, Hopewell S, Schulz KF, et al. CONSORT 2010 explanation and elaboration: updated guidelines for reporting parallel group randomised trials. BMJ. 2010;340:c869. http://www.ncbi.nlm.nih. gov/pmc/articles/PMC2844943/.
37. Steckler A, Linnan L. Process Evaluation for Public Health Interventions and Research. San Francisco, CA: Jossey-Bass; 2002:432.

38. McCall DT, Sauaia A, Hamman RF, Reusch JE, Barton P. Are low-income elderly patients at risk for poor diabetes care? Diabetes Care. 2004;27(5):1060-1065. http://www.ncbi.nlm.nih.gov/ pubmed/15111521.

39. Woodwell DA, Cherry DK. National Ambulatory Medical Care Survey: 2002 summary. Adv Data. 2004;(346):1-44. http://www.ncbi. nlm.nih.gov/pubmed/15460863.

40. Andrus MR, Kelley KW, Murphey LM, Herndon KC. A comparison of diabetes care in rural and urban medical clinics in Alabama. J Community Health. 2004;29(1):29-44. http://www.ncbi.nlm.nih.gov/ pubmed/14768933.

41. Zoorob RJ, Mainous AG III. Practice patterns of rural family physicians based on the American Diabetes Association standards of care. J Community Health. 1996;21(3):175-182. http://www.ncbi.nlm. nih.gov/pubmed/8726208.

42. Lujan J, Ostwald SK, Ortiz M. Promotora diabetes intervention for Mexican Americans. Diabetes Educ. 2007;33(4):660-670.

43. Bray $P$, Cummings DM, Morrissey $S$, et al. Improved outcomes in diabetes care for rural African Americans. Ann Fam Med. 2013:11(2):145-150.

44. Brown SA, Garcia AA, Kouzekanani K, Hanis CL. Culturally competent diabetes self-management education for Mexican Americans: the Starr County border health initiative. Diabetes Care. 2002;25(2):259-268. http://www.ncbi.nlm.nih.gov/pmc/articles/ PMC2134805/.

45. Philis-Tsimikas A, Fortmann A, Lleva-Ocana L, Walker C, Gallo LC. Peer-led diabetes education programs in high-risk Mexican Americans improve glycemic control compared with standard approaches: a Project Dulce promotora randomized trial. Diabetes Care. 2011;34(9):1926-1931.

46. Lorig K, Ritter PL, Villa F, Piette JD. Spanish diabetes selfmanagement with and without automated telephone reinforcement: two randomized trials. Diabetes Care. 2008;31(3):408-414.

47. Collinsworth AW, Vulimiri M, Schmidt KL, Snead CA. Effectiveness of a community health worker-led diabetes self-management education program and implications for CHW involvement in care coordination strategies. Diabetes Educ. 2013;39(6):792-799.

48. Gucciardi E, Chan VW-S, Manuel L, Sidani S. A systematic literature review of diabetes self-management education features to improve diabetes education in women of Black African/Caribbean and Hispanic/Latin American ethnicity. Patient Educ Couns. 2013;92(2):235-245.

49. Elder JP, Ayala GX, Campbell NR, et al. Long-term effects of a communication intervention for Spanish-dominant Latinas. Am J Prev Med. 2006;31(2):159-166.

50. Ayala GX, Ibarra L, Binggeli-Vallarta A, et al. Our choice/nuestra opción: the Imperial County, California Childhood Obesity Research Demonstration study (CA-CORD). Child Obes. 2015;11(1):37-47.

51. Bodenheimer T, Wagner EH, Grumbach K. Improving primary care for patients with chronic illness. JAMA. 2002;288(14):1775-1779. http://www.ncbi.nlm.nih.gov/pubmed/12365965.

52. Renders CM, Valk GD, Griffin S, Wagner EH, Eijk JT, Assendelft WJ. Interventions to improve the management of diabetes mellitus in primary care, outpatient and community settings. Cochrane Database Syst Rev. 2001;1(1):CD001481.

53. Pimouguet C, Le Goff M, Thiébaut R, Dartigues JF, Helmer C. Effectiveness of disease-management programs for improving diabetes care: a meta-analysis. CMAJ. 2011;183(2):E115-E127.

54. Blanck HM, Gillespie C, Kimmons JE, Seymour JD, Serdula MK. Trends in fruit and vegetable consumption among U.S. men and women, 1994-2005. Prev Chronic Dis. 2008;5(2):A35. http://www. ncbi.nlm.nih.gov/pmc/articles/PMC2396974/. 